\title{
Substrate Turnover during Prolonged Exercise in Man
}

\author{
SPLANCHNIC AND LEG METABOLISM OF \\ GLUCOSE, FREE FATTY ACIDS, AND AMINO ACIDS
}

\author{
Gunvor Ahlborg, Philip Felig, Lars Hagenfeldt, Rosa Hendler, and \\ JOHN WAHREN
}

\begin{abstract}
From the Departments of Clinical Physiology and Clinical Chemistry, the
Karolinska Institute at the Serafimer Hospital, Stockholm, Sweden and the

Department of Internal Medicine, Yale University School of Medicine, New Haven, Connecticut 06510
\end{abstract}

A B S T RACT Arterial concentrations and substrate exchange across the leg and splanchnic vascular beds were determined for glucose, lactate, pyruvate, glycerol, individual acidic and neutral amino acids, and free fatty acids (FFA) in six subjects at rest and during $4 \mathrm{~h}$ of exercise at approximately $30 \%$ of maximal oxygen uptake. FFA turnover and regional exchange were evaluated using ${ }^{14} \mathrm{C}$-labeled oleic acid.

The arterial glucose concentration was constant for the first 40 min of exercise, but fell progressively thereafter to levels $30 \%$ below basal. The arterial insulin level decreased continuously, while the arterial glucagon concentration had risen fivefold after $4 \mathrm{~h}$ of exercise. Uptake of glucose and FFA by the legs was markedly augmented during exercise, the increase in FFA uptake being a consequence of augmented arterial levels rather than increased fractional extraction. As exercise was continued beyond $40 \mathrm{~min}$, the relative contribution of FFA to total oxygen metabolism rose progressively to $62 \%$. In contrast, the contribution from glucose fell from $40 \%$ to $30 \%$ between 90 and $240 \mathrm{~min}$. Leg output of alanine increased as exercise progressed.

Splanchnic glucose production, which rose $100 \%$ above basal levels and remained so throughout exercise, exceeded glucose uptake by the legs for the first $40 \mathrm{~min}$ but thereafter failed to keep pace with peripheral glucose

Dr. Felig is recipient of a Research Career Development Award (AM 70219) from the National Institutes of Health.

Address reprint requests to Dr. Felig at the Department of Internal Medicine, Yale University School of Medicine, New Haven, Conn. 06510.

Received for publication 9 July 1973 and in revised form 26 November 1973. utilization. Total estimated splanchnic glucose output was $75 \mathrm{~g}$ in $4 \mathrm{~h}$, sufficient to deplete approximately $75 \%$ of liver glycogen stores. Splanchnic uptake of gluconeogenic precursors (lactate, pyruvate, glycerol, alanine) had increased 2 - to 10 -fold after $4 \mathrm{~h}$ of exercise, and was sufficient to account for $45 \%$ of glucose release at $4 \mathrm{~h}$ as compared to $20-25 \%$ at rest and at $40 \mathrm{~min}$ of exercise. In the case of alanine and lactate, the increase in precursor uptake was a consequence of a rise in splanchnic fractional extraction.

It is concluded that during prolonged exercise at a low work intensity $(a)$ blood glucose levels fall because hepatic glucose output fails to keep up with augmented glucose utilization by the exercising legs; $(b)$ a large portion of hepatic glycogen stores is mobilized and an increasing fraction of the splanchnic glucose output is derived from gluconeogenesis; (c) blood-borne substrates in the form of glucose and FFA account for a major part of leg muscle metabolism, the relative contribution from FFA increasing progressively; and (d) augmented secretion of glucagon may play an important role in the metabolic adaptation to prolonged exercise by its stimulatory influence on hepatic glycogenolysis and gluconeogenesis.

\section{INTRODUCTION}

Recent studies have demonstrated that blood glucose plays an important role in the substrate supply of exercising skeletal muscle during short-term exercise $(1 \mathrm{~h}$ or less) in man. During forearm as well as leg exercise, glucose uptake by working muscle rises 20 - to 35 -fold above the basal level, the increment being a function of both intensity and duration of work $(1,2)$. If oxidized, 
TABLE I

Age, Height, Weight, Maximal Oxygen Uptake, and Work Load During Prolonged Exercise

\begin{tabular}{|c|c|c|c|c|c|c|}
\hline Subject & Age & Height & Weight & $\begin{array}{l}\text { Maximal oxygen } \\
\text { uptake }\end{array}$ & $\begin{array}{l}\text { Studied at work } \\
\text { load during pro- } \\
\text { longed exercise }\end{array}$ & $\begin{array}{l}\text { Oxygen uptake } \\
\text { during exercise* }\end{array}$ \\
\hline & $y r$ & $\mathrm{~cm}$ & kg & liter $/ \min$ & $W \ddagger$ & $\%$ of max. \\
\hline K. G. & 28 & 184 & 73 & 4.49 & 105 & 37 \\
\hline U. G. & 24 & 178 & 75 & 3.80 & 75 & 34 \\
\hline B. D. & 31 & 190 & 82 & 4.57 & 90 & 29 \\
\hline L. P. & 26 & 175 & 72 & 3.50 & 65 & 31 \\
\hline T. H. & 32 & 176 & 74 & 3.45 & 65 & 31 \\
\hline O. K. & 27 & 178 & 80 & 4.00 & 80 & 30 \\
\hline
\end{tabular}

* Measured at $40 \mathrm{~min}$ of exercise.

$\ddagger$ Watts (1 watt $=6.135 \mathrm{~kg}-\mathrm{m} / \mathrm{min})$.

the glucose taken up may support as much as $30-50 \%$ of the oxidative metabolism of exercising muscle $(1,2)$. The blood glucose pool is replenished continuously during exercise of up to $1 \mathrm{~h}$ duration by a three- to fivefold increase in glucose release from the liver $(3,4)$, the major part being derived from hepatic glycogen mobilization $(2,5)$. Quantitative assessments based on estimated hepatic glycogen stores of $75-90 \mathrm{~g}$ in postabsorptive man (5) suggest that the above rate of hepatic glycogenolysis can be maintained for only a limited period of time. Maintenance of glucose homeostasis in prolonged exercise thus necessitates an increase in gluconeogenesis, a diminution of glucose uptake by muscle, or a combination of these mechanisms. Glucose turnover and gluconeogenesis in prolonged exercise have been evaluated by indirect isotopic techniques (6), but direct measurements of splanchnic and peripheral substrate exchange have not been reported in prolonged exercise.

The current study was undertaken to examine quantitatively the uptake of blood glucose and free fatty acid (FFA) by working muscle and to evaluate the role of hepatic glycogenolytic and gluconeogenic processes in the maintenance of glucose homeostasis during prolonged exercise. This was done by the simultaneous determination of leg and splanchnic exchange of substrates during bicycle exercise for $4 \mathrm{~h}$ in healthy postabsorptive subjects. In addition, data are reported on arterial insulin and glucagon levels during prolonged exercise.

\section{METHODS}

Subjects. Six healthy male volunteers were studied in the postabsorptive state after a $12-14 \mathrm{~h}$ overnight fast. In Table I data on age, height, weight, and maximal oxygen uptake are given. The maximal oxygen uptake was determined 2-3 wk before the study during bicycle exercise at stepwise increased workloads. During the week immediately before the study, the subjects ingested a weightmaintaining diet containing 2,400-4,000 kcal/day (mean
$3,300 \mathrm{kcal}$ ), consisting of $55 \%$ carbohydrate, $30 \%$ fat, and $15 \%$ protein. None of the subjects participated in training programs or competitive athletics on a regular basis. All subjects were informed of the nature, purpose, and possible risks involved in the study before giving their voluntary consent to participate.

Procedure. The subjects were studied during a $30-\mathrm{min}$ rest period and during upright continuous bicycle exercise for $4 \mathrm{~h}$ at a work load corresponding to approximately $30 \%$ of their maximal oxygen uptake (Table I). Teflon catheters were inserted percutaneously into both femoral veins, a femoral artery, and an antecubital vein. A Cournand catheter (no. 8) was introduced percutaneously into a medial antecubital vein and advanced to a right-sided hepatic vein under fluoroscopic control. Patency of the catheters was maintained by intermittent flushing with saline; the hepatic venous catheter was flushed with $1.5 \%$ sodium citrate solution, a total of less than $0.3 \mathrm{~g}$ being administered to the subject.

In the resting state and after $40,90,180$, and $240 \mathrm{~min}$ of exercise, expired air was collected for the determination of pulmonary oxygen uptake; heart rate was recorded; and arterial, femoral venous, and hepatic venous blood samples were collected. A mixture of $\left[{ }^{14} \mathrm{C}\right]$ oleic acid $(0.5$ $\mu \mathrm{Ci} / \mathrm{min}$, specific activity $59 \mathrm{mCi} / \mathrm{mmol}$, NEN Chemicals, Dreieichenhain, Germany) bound to human albumin and indocyanine green dye was infused intravenously at a constant rate to enable estimation of oleic acid turnover and regional exchange as well as hepatic blood flow (7, 8). The latter infusions were started at $20,70,160$, and $220 \mathrm{~min}$ of exercise and continued for $20 \mathrm{~min}$; three blood samples for determinations of plasma FFA radioactivity and dye concentration were obtained between 15 and 20 min of infusion. Constant oleic acid specific activities were observed in all subjects during the measuring periods (Fig. 1). Leg blood flow was determined by infusion of indocyanine green dye (9). Total blood loss during the study was less than $450 \mathrm{ml}$.

Analyses. Glucose (10), lactate (11), pyruvate (12), and glycerol (13) were analyzed in whole blood by using enzymatic techniques. Individual neutral and acidic amino acids in plasma were determined after deproteinization with sulfosalicylic acid by the automated ion-exchange chromatographic technique (14). Total FFA and oleic acid concentrations in plasma were analyzed by gas chromatography, using heptadecanoic acid as an internal standard $(15,16)$. 


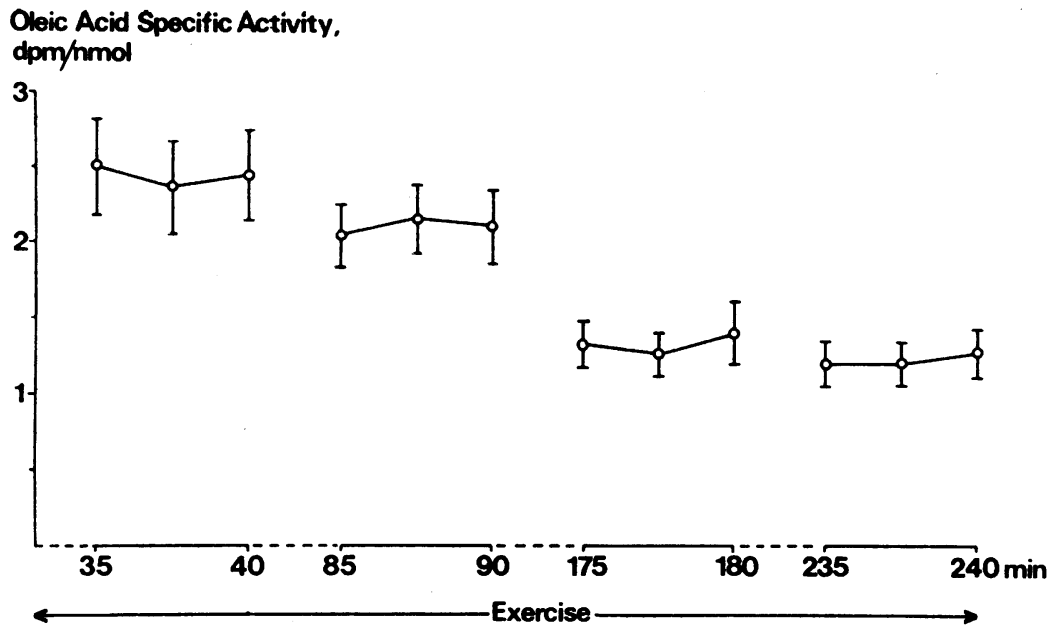

FIGURE 1 Oleic acid specific activity (mean \pm SEM) during the final 5 min of each measuring period during exercise.

The FFA radioactivity was determined on a heptane extract with subsequent correction for the radioactivity of esterified fatty acids remaining in the heptane after extraction of the free acids into alkaline $70 \%$ methanol. Plasma insulin and glucagon were analyzed by radioimmunoassay $(17,18)$. Oxygen saturation was measured spectrophotometrically (19) and hemoglobin concentration by the cyanmethemoglobin technique (20). Hematocrit was measured by using a microcapillary centrifuge and corrected for trapped plasma (21). Expired air was analyzed with the Scholander microtechnique.

Calculations. The fractional uptake (f) of oleic acid across the leg and splanchnic vascular beds was calculated on the basis of its arterial (A) and venous (V) radioactivity : $f={ }^{14} \mathrm{C}-18: 1_{\Delta-\nabla} /{ }^{14} \mathrm{C}-18: 1_{\Delta \text {. }}$ The uptake of oleic acid ( $\mathrm{U}, \mu \mathrm{mol} / \mathrm{min})$ by the leg or the splanchnic area was calculated as the product of $f$, the arterial plasma concentration of free oleic acid, and the plasma flow (P). Release of oleic acid $(R, \mu \mathrm{mol} / \mathrm{min})$ was estimated as the difference between $U$ and the net exchange of unlabeled oleic acid: $R=U-\left(18: 1_{\Delta-v}\right) \cdot P$. The turnover rate of oleic acid was calculated as the amount of radioactivity infused per unit time divided by the oleic acid specific activity. The fractional turnover of oleic acid was calculated as its turnover divided by the product of the arterial concentration times the plasma volume. These calculations have in part been reported previously (22).

Data in the text, tables, and figures are given as mean \pm SEM. Standard statistical methods have been employed, using the paired $t$ test when applicable.

TABLE II

Heart rate, Oxygen Uptake, and Estimated Splanchnic and Leg Blood Flow at Rest and during Prolonged Exercise*

\begin{tabular}{|c|c|c|c|c|c|}
\hline & \multirow[b]{2}{*}{ Rest } & \multicolumn{4}{|c|}{ Exercise } \\
\hline & & $40 \mathrm{~min}$ & $90 \mathrm{~min}$ & $180 \mathrm{~min}$ & $240 \mathrm{~min}$ \\
\hline Heart rate, beats/min & $53 \pm 2$ & $104 \pm 6$ & $108 \pm 4$ & $121 \pm 4$ & $129 \pm 5$ \\
\hline Pulmonary oxygen uptake, $\mathrm{ml} / \mathrm{min}$ & $279 \pm 13$ & $1,280 \pm 88$ & $1,302 \pm 113$ & $1,365 \pm 88$ & $1,417 \pm 94$ \\
\hline Respiratory exchange ratio & $0.72 \pm 0.02$ & $0.81 \pm 0.02$ & $0.82 \pm 0.02$ & $0.79 \pm 0.03$ & $0.76 \pm 0.01$ \\
\hline Mechanical efficiency, $\%$ & & $23.6 \pm 0.6$ & $23.4 \pm 0.8$ & $21.8 \pm 0.7$ & $20.8 \pm 0.9$ \\
\hline Leg blood flow, liters/min & $0.43 \pm 0.02$ & $2.72 \pm 0.24$ & $2.90 \pm 0.19$ & $2.94 \pm 0.22$ & $2.91 \pm 0.23$ \\
\hline A-FV oxygen difference, $m l /$ liter $\ddagger$ & $53.2 \pm 5.7$ & $124.6 \pm 4.3$ & $136.7 \pm 5.5$ & $132.7 \pm 5.9$ & $136.6 \pm 4.7$ \\
\hline Leg oxygen uptake, $\mathrm{ml} / \mathrm{min}$ & $23 \pm 3$ & $343 \pm 40$ & $396 \pm 31$ & $396 \pm 43$ & $400 \pm 38$ \\
\hline $\mathrm{EHBF} \&$ liters $/ \min$ & $1.12 \pm 0.03$ & $1.08 \pm 0.11$ & $1.00 \pm 0.10$ & $1.06 \pm 0.09$ & $1.02 \pm 0.10$ \\
\hline A-HV oxygen difference, $m l / l i t e r \|$ & $47.9 \pm 3.4$ & $74.8 \pm 7.3$ & $92.6 \pm 9.9$ & $110.0 \pm 2.1$ & $118.5 \pm 10.0$ \\
\hline Splanchnic oxygen uptake, $\mathrm{ml} / \mathrm{min}$ & $54 \pm 4$ & $82 \pm 15$ & $93 \pm 15$ & $117 \pm 11$ & $118 \pm 12$ \\
\hline Hematocrit, $\%$ & $41.4 \pm 0.4$ & $42.6 \pm 0.7$ & $42.2 \pm 0.5$ & $42.7 \pm 0.6$ & $42.5 \pm 0.9$ \\
\hline
\end{tabular}

* Data are presented as mean $\pm \mathrm{SEM}$.

$\ddagger \mathrm{A}-\mathrm{FV}=$ arterial-femoral venous.

$\S \mathrm{EHBF}=$ estimated hepatic blood flow.

$\| \mathrm{A}-\mathrm{HV}=$ arterial-hepatic venous. 
TABLE III

Arterial Concentrations of Glucose, Lactate, Pyruvate, Glycerol, Insulin, and Glucagon at Rest and During Prolonged Exercise*

\begin{tabular}{lccccc}
\hline & & \multicolumn{4}{c}{ Exercise } \\
\cline { 3 - 6 } & Rest $\neq$ & $40 \mathrm{~min}$ & $90 \mathrm{~min}$ & $180 \mathrm{~min}$ & $240 \mathrm{~min}$ \\
\hline Glucose, $\mathrm{mmol} /$ liter & $4.51 \pm 0.13$ & $4.57 \pm 0.15$ & $4.30 \pm 0.15$ & $3.53 \pm 0.19$ & $3.12 \pm 0.29$ \\
Lactate, $\mathrm{mmol} / \mathrm{liter}$ & $1.06 \pm 0.13$ & $1.31 \pm 0.11$ & $1.32 \pm 0.09$ & $1.38 \pm 0.13$ & $1.80 \pm 0.28$ \\
Pyruvate, $\mathrm{mmol} / \mathrm{liter}$ & $0.068 \pm 0.006$ & $0.087 \pm 0.008$ & $0.091 \pm 0.009$ & $0.092 \pm 0.010$ & $0.109 \pm 0.012$ \\
Glycerol, $\mathrm{mmol} / \mathrm{liter}$ & $0.04 \pm 0.01$ & $0.19 \pm 0.03$ & $0.25 \pm 0.03$ & $0.39 \pm 0.04$ & $0.48 \pm 0.05$ \\
FFA, $\mathrm{mmol} / \mathrm{liter}$ & $0.66 \pm 0.06$ & $0.78 \pm 0.07$ & $0.93 \pm 0.12$ & $1.57 \pm 0.15$ & $1.83 \pm 0.18$ \\
Glucagon, $\mathrm{Pg} / \mathrm{ml}$ & $75 \pm 15$ & $76 \pm 16$ & $99 \pm 17$ & $201 \pm 67$ & $408 \pm 103$ \\
Insulin, $\mu \mathrm{U} / \mathrm{ml}$ & $13.9 \pm 1.9$ & $12.3 \pm 1.6$ & $10.0 \pm 1.4$ & $7.2 \pm 1.9$ & $6.2 \pm 1.4$ \\
\hline
\end{tabular}

* Data presented as mean \pm SEM.

$\ddagger$ Data for the resting state represent the mean of two to three observation s at 5- to 10 -min intervals in each subject.

\section{RESULTS}

Heart rate, pulmonary and splanchnic oxygen uptake, and blood flows (Table II). After $40 \mathrm{~min}$ of exercise the heart rate had increased about twofold over the resting value. During continued exercise it showed a small progressive elevation $(P<0.01)$, rising to $129 \pm 5$ after $4 \mathrm{~h}$ work. The pulmonary oxygen uptake had risen approximately fourfold after $40 \mathrm{~min}$ of exercise, and rose a further $10 \%$ during continued exercise $(P<0.01)$. The ventilatory exchange ratio rose from a resting value of $0.72 \pm 0.02$ to $0.82 \pm 0.02(P<0.01)$ after $90 \mathrm{~min}$ work and then gradually fell during the remaining exercise period.

Leg blood flow rose approximately sixfold from rest to exercise and then remained essentially unchanged during the exercise period. Similarly, leg oxygen uptake increased approximately 16-fold and was then largely unaltered during exercise. Estimated hepatic blood flow did not change significantly from resting values during the exercise period. In contrast, splanchnic uptake of

TABLE IV

Arterial Concentrations, Splanchnic Exchange, and Leg Exchange of Individual Neutral and Acidic Plasma Amino Acids at Rest and During Prolonged Exercise*

\begin{tabular}{|c|c|c|c|c|c|c|c|c|c|}
\hline & \multicolumn{3}{|c|}{ Arterial concentration } & \multicolumn{3}{|c|}{ Splanchnic exchange } & \multicolumn{3}{|c|}{ Leg exchange $\ddagger$} \\
\hline & \multirow[b]{2}{*}{ Rest } & \multicolumn{2}{|c|}{ Exercise } & \multirow[b]{2}{*}{ Rest } & \multicolumn{2}{|c|}{ Exercise } & \multirow[b]{2}{*}{ Rest } & \multicolumn{2}{|c|}{ Exercise } \\
\hline & & $40 \mathrm{~min}$ & $240 \mathrm{~min}$ & & $40 \mathrm{~min}$ & $240 \mathrm{~min}$ & & $40 \mathrm{~min}$ & $240 \mathrm{~min}$ \\
\hline & \multicolumn{3}{|c|}{$\mu m o l / l i t e r$} & \multicolumn{3}{|c|}{$\mu \mathrm{mol} / \mathrm{min}$} & \multicolumn{3}{|c|}{$\mu \mathrm{mol} / \mathrm{min}$} \\
\hline Taurine & $43 \pm 4$ & $46 \pm 3$ & $41 \pm 1$ & $1.9 \pm 0.4$ & $1.2 \pm 1.5$ & $-1.6 \pm 2.5$ & $1.4 \pm 1.0$ & $-9.8 \pm 7.0$ & $4.2 \pm 6.4$ \\
\hline Aspartate & $18 \pm 2$ & $21 \pm 4$ & $16 \pm 2$ & $-1.0 \pm 1.5$ & $2.7 \pm 3.1$ & $2.8 \pm 0.7$ & $-1.8 \pm 1.0$ & $1.8 \pm 4.6$ & $7.2 \pm 4.6$ \\
\hline Threonine & $112 \pm 15$ & $114 \pm 13$ & $85 \pm 168$ & $10.1 \pm 1.5$ & $16.8 \pm 4.1$ & $19.9 \pm 6.0$ & $-3.6 \pm 2.2$ & $2.2 \pm 4.4$ & $-14.6 \pm 20.4$ \\
\hline Serine & $119 \pm 10$ & $133 \pm 18$ & $99 \pm 98$ & $16.2 \pm 3.0$ & $27.2 \pm 15.9$ & $22.4 \pm 3.2$ & $5.4 \pm 2.0$ & $12.2 \pm 21.0$ & $17.0 \pm 5.4$ \\
\hline Proline & $172 \pm 10$ & $174 \pm 13$ & $131 \pm 9 \|$ & $5.7 \pm 2.5$ & $8.9 \pm 4.8$ & $15.2 \pm 2.7 \S$ & $-4.8 \pm 5.6$ & $15.8 \pm 22.6$ & $2.2 \pm 31.8$ \\
\hline Citrulline & $36 \pm 3$ & $36 \pm 2$ & $37 \pm 3$ & $-8.5 \pm 0.8$ & $-13.1 \pm 3.1$ & $-8.5 \pm 1.9$ & $2.0 \pm 0.6$ & $-4.8 \pm 6.8$ & $10.2 \pm 2.4 \|$ \\
\hline Glycine & $188 \pm 16$ & $206 \pm 11$ & $160 \pm 8$ & $8.3 \pm 2.2$ & $25.2 \pm 11.2$ & $31.8 \pm 4.6 \pi$ & $-8.0 \pm 3.8$ & $7.6 \pm 15.2$ & $17.8 \pm 17.4$ \\
\hline Alanine & $192 \pm 22$ & $271 \pm 29$ व & $233 \pm 30$ & $57.6 \pm 4.3$ & $89.7 \pm 21.4$ & $119.0 \pm 18.9 \rrbracket$ & $-30.4 \pm 7.6$ & $-44.6 \pm 20.0$ & $-95.4 \pm 43.68$ \\
\hline$\alpha$-Aminobutyrate & $29 \pm 3$ & $26 \pm 2$ & $22 \pm 18$ & $-3.8 \pm 3.6$ & $-2.2 \pm 1.9$ & $13.8 \pm 11.2$ & $0.2 \pm 0.4$ & $3.4 \pm 3.8$ & $5.8 \pm 4.4$ \\
\hline Valine & $242 \pm 13$ & $238 \pm 11$ & $243 \pm 9$ & $-3.2 \pm 1.5$ & $-9.1 \pm 6.0$ & $-31.6 \pm 6.8$ ฯ & $0.6 \pm 3.8$ & $31.6 \pm 17.0$ & $43.4 \pm 15.6 \|$ \\
\hline Cystine & $84 \pm 15$ & $92 \pm 11$ & $102 \pm 12$ & $3.5 \pm 1.3$ & $-1.3 \pm 6.0$ & $5.7 \pm 4.2$ & $6.2 \pm 2.6$ & $35.2 \pm 16.0$ & $23.6 \pm 20.8$ \\
\hline Methionine & $17 \pm 2$ & $19 \pm 2$ & $18 \pm 1$ & $3.4 \pm 0.6$ & $2.6 \pm 1.5$ & $4.9 \pm 1.2$ & $-0.6 \pm 0.4$ & $-2.8 \pm 2.6$ & $-4.0 \pm 4.6$ \\
\hline Isoleucine & $60 \pm 4$ & $60 \pm 2$ & $81 \pm 6 \|$ & $-1.0 \pm 0.8$ & $-2.9 \pm 2.5$ & $-17.2 \pm 2.99$ & $-0.4 \pm 1.2$ & $8.2 \pm 8.0$ & $21.8 \pm 4.2 ף$ \\
\hline Leucine & $126 \pm 7$ & $127 \pm 4$ & $151 \pm 10 \S$ & $-2.2 \pm 0.8$ & $-8.8 \pm 3.5$ & $-30.2 \pm 4.7 \Phi$ & $-0.8 \pm 2.0$ & $13.2 \pm 10.4$ & $28.6 \pm 7.8 \pi$ \\
\hline Tyrosine & $45 \pm 4$ & $49 \pm 5$ & $59 \pm 3 \|$ & $5.1 \pm 0.3$ & $4.7 \pm 1.0$ & $6.5 \pm 1.4$ & $-1.2 \pm 0.8$ & $9.0 \pm 7.6$ & $8.4 \pm 9.4$ \\
\hline Phenylalanine & $44 \pm 3$ & $49 \pm 3$ & $55 \pm 48$ & $2.3 \pm 0.5$ & $3.0 \pm 1.1$ & $4.1 \pm 2.5$ & $-1.0 \pm 0.6$ & $7.6 \pm 7.6$ & $5.2 \pm 9.0$ \\
\hline
\end{tabular}

* Data are presented as mean \pm SEM.

¥ Data refer to amino acid exchange across both legs.

8 Significantly different from the corresponding value at rest, $P<0.05$ (paired $t$ test)

|| Significantly different from the corresponding value at rest, $P<0.02$ (paired $t$ test).

I Significantly different from the corresponding value at rest, $P<0.005$ (paired $t$ test). 
TABLE V

Arterial Concentrations, Turnover, Fractional Turnover, Splanchnic Exchange, and Leg Exchange of Oleic Acid at Rest and During Prolonged Exercise*

\begin{tabular}{|c|c|c|c|c|c|}
\hline & \multirow[b]{2}{*}{ Kest $\ddagger$} & \multirow[b]{2}{*}{$40 \mathrm{~min}$} & \multicolumn{2}{|c|}{ Exercise } & \multirow[b]{2}{*}{$240 \mathrm{~min}$} \\
\hline & & & $90 \mathrm{~min}$ & $180 \mathrm{~min}$ & \\
\hline Arterial concentration of oleic acid, $\mu \mathrm{mol} /$ liter & $230 \pm 22$ & $275 \pm 27$ & $333 \pm 48$ & $576 \pm 62$ & $675 \pm 76 \S$ \\
\hline Turnover of oleic acid, $\mu \mathrm{mol} / \mathrm{min}$ & $231 \pm 19$ & $469 \pm 43$ & $543 \pm 66$ & $838 \pm 71$ & $904 \pm 79 \S$ \\
\hline Fractional turnover of oleic acid, $\min ^{-1}$ & $0.29 \pm 0.02$ & $0.55 \pm 0.01$ & $0.53 \pm 0.03$ & $0.48 \pm 0.03$ & $0.44 \pm 0.03 \S$ \\
\hline \multicolumn{6}{|l|}{ Leg exchange of oleic acid } \\
\hline $\begin{array}{l}\text { Fractional uptake } \\
\text { Rate of exchange (both legs), } \mu \mathrm{mol} / \mathrm{min}\end{array}$ & $0.46 \pm 0.03$ & $0.19 \pm 0.03$ & $0.17 \pm 0.02$ & $0.14 \pm 0.02$ & $0.15 \pm 0.02$ \\
\hline $\begin{array}{l}\text { Uptake } \\
\text { Release }\end{array}$ & $\begin{array}{l}46 \pm 5 \\
52 \pm 6\end{array}$ & $\begin{array}{r}135 \pm 19 \\
98 \pm 15\end{array}$ & $\begin{array}{r}170 \pm 32 \\
86 \pm 25\end{array}$ & $\begin{array}{l}229 \pm 40 \\
183 \pm 69\end{array}$ & $\begin{array}{l}308 \pm 59 \| \\
200 \pm 95\end{array}$ \\
\hline \multicolumn{6}{|l|}{ Splanchnic exchange of oleic acid } \\
\hline $\begin{array}{l}\text { Fractional uptake } \\
\text { Rate of exchange, } \mu \mathrm{mol} / \mathrm{min}\end{array}$ & $0.37 \pm 0.03$ & $0.29 \pm 0.08$ & $0.38 \pm 0.04$ & $0.45 \pm 0.04$ & $0.45 \pm 0.04$ \\
\hline $\begin{array}{l}\text { Uptake } \\
\text { Release }\end{array}$ & $\begin{array}{r}55 \pm 7 \\
6 \pm 1\end{array}$ & $\begin{array}{l}63 \pm 9 \\
49 \pm 7\end{array}$ & $\begin{array}{l}76 \pm 13 \\
38 \pm 8\end{array}$ & $\begin{array}{r}159 \pm 20 \\
54 \pm 18\end{array}$ & $\begin{array}{c}172 \pm 15 \S \\
66 \pm 16\end{array}$ \\
\hline
\end{tabular}

* Data presented as mean $\pm \mathrm{SEM}$.

$\ddagger$ Data for the basal state represent the mean of three observations with 5- to 10-min intervals.

$\S$ Significantly different from value at $40 \mathrm{~min}$ of exercise, $P<0.01$.

$\|$ Significantly different from value at $40 \mathrm{~min}$ of exercise, $P<0.05$.

oxygen rose progressively during the first $180 \mathrm{~min}$ of exercise, reaching values $120 \%$ above the basal level $(P<0.001)$.

Arterial concentrations. The arterial levels of glu- cose, lactate, pyruvate, and glycerol are presented in Table III. The arterial concentration of glucose after 40 min of exercise was not significantly different from the basal value, but a gradual decline occurred after

TABLE VI

Arterio-Venous Difference and Exchange of Glucose and Gluconeogenic Precursors Across the Splanchnic and Leg Vascular Beds at Rest and During Prolonged Exercise*

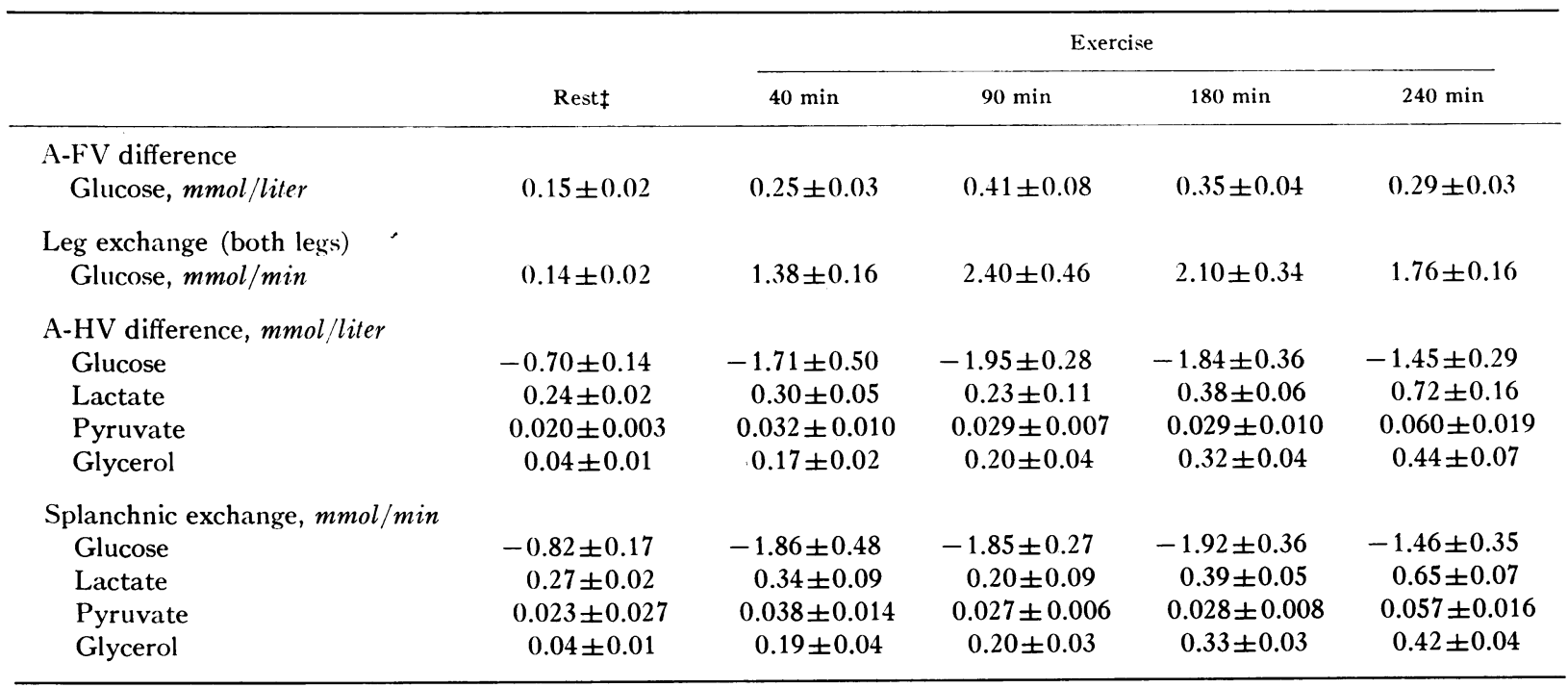

* Data are presented as mean \pm SEM.

$\ddagger$ Data for the resting state represent the mean of two to three observations at 5- to 10 -min intervals in each subject. 


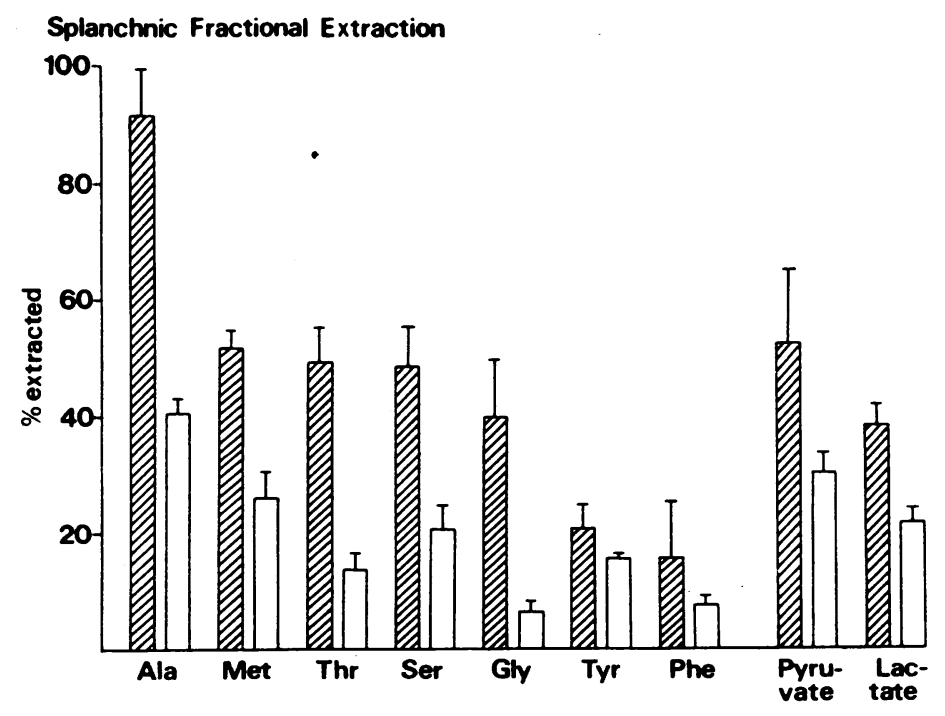

Figure 2 Fractional extraction of amino acids, lactate and pyruvate by the splanchnic vascular bed after $4 \mathrm{~h}$ of exercise (cross-hatched bars) and in the basal state (open bars).

$40 \mathrm{~min}$. At the end of the exercise period the glucose level was approximately $70 \%$ of the basal value $(P<$ $0.005)$. The arterial lactate level was not influenced significantly by the light exercise performed, though a small increase was noted at $240 \mathrm{~min}$ of exercise. The arterial pyruvate concentration rose slightly during exercise $(P<0.01)$. The arterial concentration of glycerol increased progressively throughout the exercise period, reaching a concentration at $4 \mathrm{~h}$ which was approximately 12 -fold above the basal value.

The arterial concentration of alanine (Table IV) rose $40 \%$ above the resting level after $40 \mathrm{~min}$ of exercise $(P<0.001)$, while all other amino acids showed no significant change. A direct linear relationship was found between arterial pyruvate and alanine levels obtained at rest and at $40 \mathrm{~min}$ of exercise $(r=0.85, P<$ 0.001 ). Between $40 \mathrm{~min}$ and $4 \mathrm{~h}$ of exercise, a decrease was observed in the arterial level of alanine as well as of threonine, serine, proline, glycine, and $\alpha$-aminobutyrate $(P<0.01-0.05)$. The concentrations of leucine, isoleucine, tyrosine, and phenylalanine increased slightly $(P<0.05)$.

The arterial concentrations of total FFA (Table III) and of oleic acid (Table $\mathrm{V}$ ) rose during the exercise period $(P<0.01)$, reaching values at the end of this period that were approximately threefold above the basal level. The turnover rate of oleic acid (Table V) also rose substantially during exercise. A direct linear relationship was observed between the turnover rate and the arterial concentration of oleic acid $(r=$ $0.96, P<0.001)$. However, the increment in the arterial concentration of oleic acid which occurred between 40 and $240 \mathrm{~min}$ was proportionately greater than the incre- ment in the turnover rate. Consequently the fractional turnover decreased as the exercise was continued for $240 \min$ (Table V).

The arterial level of glucagon (Table III) remained essentially unchanged during the first $90 \mathrm{~min}$ of exercise, but rose markedly during the latter half of the exercise period. At $4 \mathrm{~h}$ of exercise the glucagon concentration had risen more than fivefold above the basal level. Plasma glucagon correlated negatively with the arterial glucose concentration $(r=-0.70, \quad P<0.001)$ and positively with the arterial FFA concentration $(r=0.87$, $P<0.001$ ). The arterial insulin level (Table III) declined progressively during exercise and was after $4 \mathrm{~h}$ less than half the basal value. A positive correlation was noted between arterial insulin and glucose levels $(r=$ $0.53, P<0.01$ ).

Leg exchange of substrates. Glucose uptake by the leg (Table VI) after $40 \mathrm{~min}$ of exercise was about 10 times the basal value. The peak rise, 17 -fold above basal, was seen after $90 \mathrm{~min}$, followed by a slight gradual decrease during the rest of the exercise period. Nevertheless, at $4 \mathrm{~h}$ of exercise, glucose uptake was 12 times the basal value and $30 \%$ higher than at $40 \mathrm{~min}$.

With respect to leg amino acid exchange (Table IV), alanine was the only amino acid consistently released during exercise. Net output of alanine showed a modest increment at $40 \mathrm{~min}$ and rose to three times basal levels after $240 \mathrm{~min}$ of exercise. Net uptakes by the leg of the branched chain amino acids (valine, leucine, and isoleucine) and of serine and citrulline were observed after $240 \mathrm{~min}$ of exercise $(P<0.05-0.005)$.

The rate of oleic acid uptake by the legs (Table V) was augmented approximately threefold after $40 \mathrm{~min}$ of 


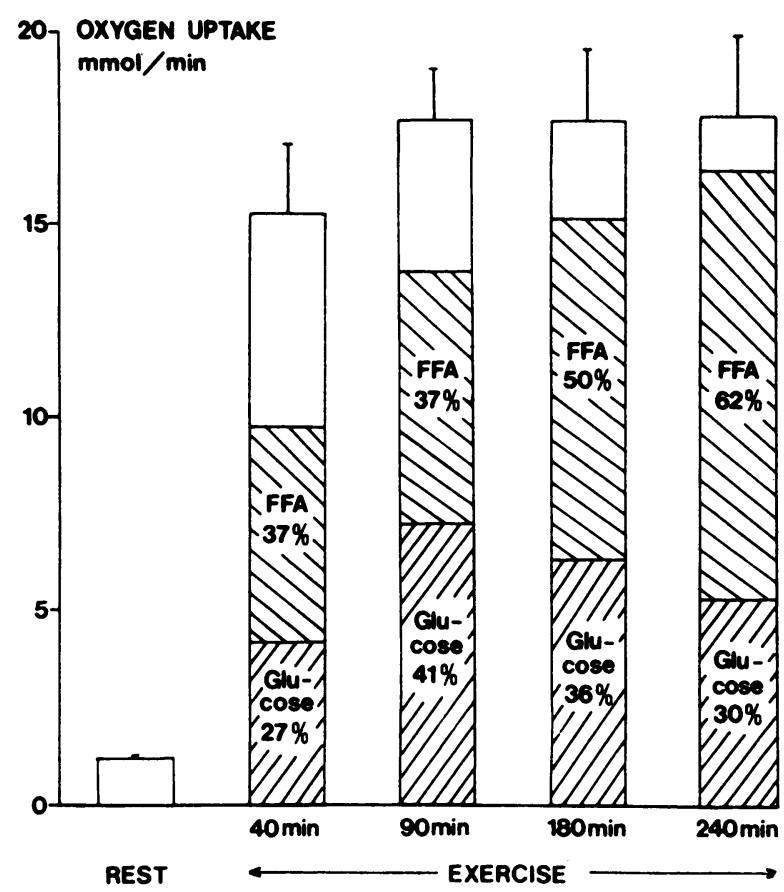

Figure 3 Leg uptake of oxygen and substrates in the basal state and during exercise. The height of the bars represents the mean ( \pm SEM) oxygen uptake. The crosshatched areas indicate FFA and glucose uptake expressed in oxygen equivalents. The percent values represent the proportion of total oxygen uptake contributed by oxidation of these substrates.

exercise compared with the resting state and a further $140 \%$ rise was seen during the remainder of the exercise period $(P<0.05)$. In contrast, the fractional uptake of oleic acid by the leg fell from rest to exercise, followed by a small further decrease as exercise continued. Uptake of oleic acid by the legs accounted for approximately $35 \%$ of oleic acid turnover during the entire exercise period. The rate of release of oleic acid from the leg rose with the onset of exercise and was further approximately doubled during the latter part of exercise.

Splanchnic exchange of substrates. The splanchnic glucose output (Table VI) rose more than twofold from rest to $40 \mathrm{~min}$ of exercise and then remained essentially unchanged during exercise, apart from a small decline at the end of the exercise period.

The splanchnic uptake of glucose precursors (Table VI) increased during the latter part of the exercise period. Lactate uptake rose approximately twofold $(P<$ $0.005)$, while pyruvate $(P<0.05)$ and glycerol uptake $(P<0.001)$ increased 3 - to 11 -fold. In the case of lactate, the augmented splanchnic uptake was a consequence of increased fractional extraction (basal: $22 \pm 2 \% ; 240$ min exercise; $38 \pm 3 \% ; P<0.01$, (Fig. 2). In contrast, the rise in glycerol uptake resulted from the marked, progressive increase in arterial concentration, the fractional extraction of glycerol remaining at $80-83 \%$.

Table IV presents the splanchnic exchange of individual amino acids. After $240 \mathrm{~min}$ of exercise, alanine uptake had increased $100 \%$ above the resting value $(P<$ $0.005)$. Similarly, the splanchnic uptake of threonine, serine, proline, and glycine $(P<0.05-0.01)$ rose during prolonged exercise. The increased uptake of these amino acids was a consequence of augmented fractional uptake by the splanchnic bed (Fig. 2); fractional uptake of alanine rose from $40 \pm 3 \%$ in the basal state to $57 \pm 3 \%$ at $40 \mathrm{~min}$ of exercise $(P<0.025)$, a further rise to $87 \pm 8 \%$ was noted at $4 \mathrm{~h}$ of exercise $(P<0.025)$. Comparable increments in fractional extraction were observed for threonine, serine, proline, glycine, and methionine $(P<0.05-0.001$, Fig. 2). In contrast, a significant splanchnic output of valine, isoleucine, and leucine $(P<0.005-0.001)$ was observed after $4 \mathrm{~h}$ of exercise.

The rate of splanchnic uptake of oleic acid increased most markedly during the latter part of the exercise period, reaching 3 times the values observed at rest (Table V). Splanchnic fractional uptake of $\left[{ }^{14} \mathrm{C}\right]$ oleic acid during the prolonged exercise period also increased from 29 to $45 \%$. Splanchnic uptake of oleic acid, expressed as a percent of the total oleic acid turnover, increased during exercise from 13 to $19 \%(P<0.05)$. The release of oleic acid from the splanchnic area rose markedly during the first $40 \mathrm{~min}$ of exercise and then remained unchanged as exercise continued for $4 \mathrm{~h}$.

\section{DISCUSSION}

In the present study the arterial concentrations of substrates changed gradually throughout the exercise period thereby complicating the calculations of regional substrate exchange. However, the rate of change of the arterial levels of glucose, lactate, pyruvate, glycerol. and FFA was no more than $0.2-0.5 \% \cdot \mathrm{min}^{-1}$. Considering the mean circulation time of the leg and splanchnic vascular beds, the change in arterial concentration introduces a maximum error in the calculations of regional exchange of no more than $1-2 \%$ of the estimated values. This factor appears negligible in relation to other, nonsystematic methodological errors inherent in the procedures employed. In this context it is noteworthy that, because of the rapid turnover of plasma FFA (Table V), a stable level of oleic acid specific activity was in fact achieved during each measuring period (Fig. 1) thus permitting calculations of oleic acid turnover and regional exchange.

Previous studies have demonstrated that the rate of glucose utilization by working muscle rises during exercise of up to $40 \mathrm{~min}$ duration $(1,2)$. The current 
findings establish that this high rate of glucose uptake increases further as exercise continues for $3 \mathrm{~h}$. Not until after $4 \mathrm{~h}$ of exercise, when the arterial glucose concentration had decreased by $30 \%$, was a small decline in glucose consumption noticeable, although the value still exceeded that seen after $40 \mathrm{~min}$ of exercise. It is noteworthy that a high rate of glucose uptake by muscle is thus maintained even though the arterial level of insulin falls during exercise. This finding is in accordance with previous observations relevant to shorter periods of exercise (23) and underscores the hypothesis that glucose uptake by exercising muscle is not dependent on the ability to secrete increased amounts of insulin (24).

The measurements of substrate uptake by the exercising leg allow a direct estimate of the contribution made by each fuel to total oxidative metabolism. Fig. 3 shows the contribution of FFA and blood glucose (in oxygen equivalents) to total oxygen uptake by the exercising leg. As indicated, the estimated glucose contribution reaches a peak at $90 \mathrm{~min}$ of exercise and then declines. In contrast, the fraction of total metabolism that could be attributed to FFA uptake increased progressively, so that by $4 \mathrm{~h}$ it exceeded the relative contribution of glucose. The combined uptakes of glucose and FFA by the exercising muscle could account for approximately $65 \%$ of the total metabolism after $40 \mathrm{~min}$, while at $4 \mathrm{~h}$ of exercise the figure had increased to more than $90 \%$. These findings thus demonstrate that during prolonged exercise of this type, blood-borne substrates, particularly FFA, play an increasingly important role in the supply of fuel to exercising muscle. The results also indicate that the previously suggested inhibitory influence of FFA on glucose uptake by muscle $(25,26)$ does not appear to be operative during physical exercise in man. It should be noted that the present calculations make no allowance for glucose-derived lactate or alanine production and the values given in Fig. 3 may slightly overestimate glucose metabolism, particularly at the end of the exercise period when the arterial lactate level rose slightly.

With respect to changes in FFA metabolism by the leg, it is of interest that total turnover and leg uptake of oleic acid increased progressively during exercise in association with a rising arterial concentration (Table V). In contrast, fractional uptake of oleic acid by the leg was lower during exercise than at rest and tended to fall throughout the exercise period. These data thus indicate that uptake of FFA by exercising muscle is primarily determined by substrate presentation, as suggested from earlier studies (27).

Splanchnic glucose output changed little between 40 and $180 \mathrm{~min}$ of exercise, but a moderate fall was observed at the end of the last hour of exercise. Based on linear interpolations between the different measurements during exercise, total glucose output from the liver
TABLE VII

Balance of Glucose and Gluconeogenic Substrates Across the Splanchnic Vascular Bed at Rest and During Prolonged Exercise

\begin{tabular}{lccc}
\hline & & \multicolumn{2}{c}{ Exercise } \\
\cline { 3 - 4 } & & $\begin{array}{c}40 \\
\text { min }\end{array}$ & $\begin{array}{c}240 \\
\text { min }\end{array}$ \\
\hline Rest & 0.82 & 1.86 & 1.46 \\
Glucose production* & & & \\
Uptake of & 0.13 & 0.23 & 0.29 \\
(1) Lactate $\ddagger$ & 0.01 & 0.02 & 0.03 \\
(2) Pyruvate $\ddagger$ & 0.02 & 0.10 & 0.21 \\
(3) Glycerol $\ddagger$ & 0.05 & 0.09 & 0.12 \\
(4) Amino acids $\$$ & 0.21 & 0.44 & 0.65 \\
Sum of (1)-(4) & 25 & 23 & 45 \\
Percent of glucose production & & & \\
\hline
\end{tabular}

* Data are presented as millimoles per minute. $\ddagger$ Expressed as glucose equivalents in millimoles per minute. § Sum of splanchnic uptakes of aspartate, threonine, serine, proline, glycine, alanine, cystine, methionine, tyrosine, phenylalanine.

during the $4 \mathrm{~h}$ of exercise is estimated to have been $75 \mathrm{~g}$. Similarly, the maxmial contribution to glucose production which could have been made by hepatic gluconeogenesis is estimated at approximately $15-20 \mathrm{~g}$, based on the integrated splanchnic uptake of the glucose precursors lactate, pyruvate, amino acids, and glycerol (Table IV and VI). The total amount of glycogen contained in the liver in healthy postabsorptive man is reported to be 75-90 $\mathrm{g}$ (5). It thus appears that, on the average, about $3 / 4$ of the total liver glycogen stores were mobilized over the course of the $4 \mathrm{~h}$ exercise period.

Although glucose production from hepatic glycogen dominated total glucose output, particularly in the early phases of exercise, it is noteworthy that the contribution from hepatic gluconeogenesis as evaluated by substrate balance rose progressively as exercise continued. Table VII shows the balance of glucose precursors across the splanchnic bed at rest and after 40 and $240 \mathrm{~min}$ of exercise. Whereas precursor uptake could account for 23$25 \%$ of glucose release in the resting state and after $40 \mathrm{~min}$ of exercise, the figure at $4 \mathrm{~h}$ was $45 \%$. This was accompanied by marked increases in the splanchnic uptake of both oxygen and FFA (Tables I and V), findings which are compatible with augmented rates of hepatic gluconeogenesis (28). Thus as glycogen stores are depleted by prolonged exercise, gluconeogenic processes are accelerated. This response contrasts with that observed during brief periods (10-40 $\mathrm{min}$ ) of heavy exercise $(1,200 \mathrm{~kg}-\mathrm{m} / \mathrm{min})$ in which circumstance the relative contribution from gluconeogenesis declines to less than $10 \%(2)$. 
The increased uptake of glucose precursors by the splanchnic area during prolonged exercise occurred in part as a consequence of augmented fractional extractions (Fig. 2). This was the case for lactate and the glucogenic amino acids; fractional extraction of alanine by the splanchnic bed rose from $41 \%$ in the resting state to $87 \%$ after $4 \mathrm{~h}$ of exercise. In the case of alanine as well as threonine, serine, proline, and glycine, the augmented uptake during exercise occurred in the face of lowered arterial concentrations. In contrast, increased availability was the major factor responsible for the markedly elevated splanchnic uptake of glycerol; the fractional uptake of this precursor was high and largely unaltered throughout the exercise period. For FFA, increased arterial concentration as well as augmented fractional extraction contributed to the elevated splanchnic uptake during exercise.

As to the mechanism responsible for the augmented rate of substrate uptake by the splanchnic area during exercise, it is worth noting the simultaneous large increase of the arterial glucagon level. The rise in glucagon seen in the present study is comparable to or even in excess of the physiological increment observed during starvation (29). Similar, but less pronounced, rises in arterial glucagon have been reported for shortterm $(40 \mathrm{~min})$ exercise (30). A stimulatory influence of glucagon on hepatic uptake of glucose precursors and gluconeogenesis has been demonstrated in the isolated perfused liver, particularly for alanine $(31,32)$. A similar metabolic effect of glucagon has been suggested from studies in fasting man (29). Although the in vivo evidence for a gluconeogenic effect of glucagon in intact man is less compelling (33), it is possible that the rise in arterial glucagon contributed to the augmented uptake of glucose precursors in the present study, an effect which would be enhanced by the simultaneous fall in arterial insulin (34). These hormonal changes may also have favored hepatic gluconeogenesis by stimulating adipose tissue lipolysis $(35,36)$, thereby making increased quantities of glycerol and FFA available to the liver. It should be emphasized, however, that exercise-induced changes in gluconeogenesis may reflect the cumulative effect of increased secretion of growth hormone, cortisol, and catecholamines, as well as the accompanying changes in glucagon and insulin secretion.

In agreement with findings from previous studies (3740 ), the arterial concentration of glucose fell gradually during prolonged exercise. It has not previously been established whether this is a result of augmented peripheral utilization, decreased hepatic production, or both. The data in Table VI indicate that in the basal state and during the first $40 \mathrm{~min}$ of exercise, splanchnic glucose production exceeds leg uptake and the arterial glucose level is maintained. However, as exercise continues be- yond $40 \mathrm{~min}$, the data suggest that splanchnic glucose output fails to keep pace with the rise in peripheral utilization thereby providing a possible basis for the fall in arterial glucose concentration.

In accordance with earlier observations (41), plasma alanine levels were greater after $40 \mathrm{~min}$ of exercise than in the basal state. Previous studies have shown that during the initial $10-40 \mathrm{~min}$ of exercise the output of alanine from the exercising leg rises substantially while splanchnic uptake remains at basal levels (41). During continued exercise, a diminishing arterial concentration was observed (Table IV). The data suggest that this resulted from an imbalance between production and utilization rates for alanine during prolonged exercise; by 40 min splanchnic uptake was probably rising more than leg muscle output (Table IV). It should also be noted that plasma rather than whole blood was used for the amino acid determinations. Recent studies from our laboratories indicate that approximately $25 \%$ of peripheral output and splanchnic uptake of alanine occurs by way of blood cells (42). This suggests that plasma measurements of tissue exchange of this amino acid underestimate rather than overestimate the total release by the leg and uptake by splanchnic tissues.

The increased splanchnic output of the branched chain amino acids (valine, leucine, and isoleucine) and the rise in arterial leucine and isoleucine during prolonged mild exercise are of interest since similar responses have been observed with brief periods (10-40 $\mathrm{min}$ ) of heavy exercise $(1,200 \mathrm{~kg}-\mathrm{m} / \mathrm{min})(41)$. An elevation in the arterial concentration of the branched chain amino acids has also been observed in diabetes (43) and starvation (44). It is noteworthy in this regard that glucagon has been demonstrated to stimulate release of these amino acids by the isolated, perfused liver (32). Thus in addition to its effects on glycogenolysis and gluconeogenesis, the hyperglucagonemia of prolonged exercise may influence hepatic exchange of the branched chain amino acids and contribute to their accumulation in arterial blood.

In many respects the overall metabolic response to prolonged exercise is strikingly similar to that observed after 3 days of starvation. In the latter circumstance glycogen stores have been depleted (5), and the splanchnic uptake of glucose precursors has increased to maximum levels (44). In addition the rise in glucagon concentration (29) and the elevation in branched-chain amino acids (44) have reached peak levels. In contrast, more prolonged fasting is associated with a reduction in total glucose consumption $(45,46)$, and a fall in gluconeogenic precursor uptake (44), as well as a decline in circulating levels of glucagon (29) and branchedchain amino acids (44). The comparability of metabolic changes in prolonged exercise and at 3 days of starva- 
tion thus may reflect a common homeostatic mechanism directed at minimizing the fall in blood glucose associated with depletion of liver glycogen stores in the face of normal to increased rates of glucose utilization.

\section{ACKNOWLEDGMENTS}

This work was supported by grants from The Research Council of the Swedish Sports Federation, the Swedish Medical Research Council (19X-722, 19X-3108), The Swedish Society of Medical Sciences, and the U. S. Public Health Service (AM-13526).

\section{REFER ENCES}

1. Jorfeldt, L., and J. Wahren. 1970. Human forearm muscle metabolism during exercise. V. Quantitative aspects of glucose uptake and lactate production during prolonged exercise. Scand. J. Clin. Lab. Invest. 26: 73.

2. Wahren, J., P. Felig, G. Ahlborg, and L. Jorfeldt. 1971. Glucose metabolism during leg exercise in man. J. Clin. Invest. $50: 2715$.

3. Rowell, L. B., E. J. Masoro, and M. J. Spencer. 1965. Splanchnic metabolism in exercising man. J. Appl. Physiol. 20: 1032.

4. Bergström, J., and E. Hultman. 1967. A study of glycogen metabolism during exercise in man. Scand. J. Clin. Lab. Invest. 19: 218.

5. Hultman, E., and L. H. Nilsson. 1971. Liver glycogen in man. Effect of different diets and muscular exercise. In Muscle Metabolism during Exercise. B. Pernow and B. Saltin, editors. Plenum Press, New York. 143.

6. Young, D. R., R. Pelligra, J. Shapira, R. R. Adachi, and K. Skrettingland. 1967. Glucose oxidation and replacement during prolonged exercise in man. $J$. Appl. Physiol. 23 : 734.

7. Bradley, S. E. 1948. Measurement of hepatic blood flow. In Methods in Medical Research. V. R. Potter, editor. Year Book Publishers, Chicago. 1: 199.

8. Rowell, L. B., K. K. Kraning II, T. O. Evans, J. W. Kennedy, J. R. Blackmon, and F. Kusumi. 1966. Splanchnic removal of lactate and pyruvate during prolonged exercise in man. J. Appl. Physiol. 21: 1773.

9. Jorfeldt, L., and J. Wahren. 1971. Leg blood flow during exercise in man. Clin. Sci. 14: 459.

10. Huggett, A. S. T. G., and D. A. Nixon. 1957. Use of glucose oxidase, peroxidase, and o-dianisidine in determination of blood and urinary glucose. Lancet. 2: 368.

11. Wahren, J. 1966. Quantitative aspects of blood flow and oxygen uptake in the human forearm during rhythmic exercise. Acta Physiol. Scand. 67 (Suppl. 269): 1.

12. Bücher, T., R. Czok, W. Lamprecht, and E. Latzko. 1962. Pyruvat. In Methoden der enzymatischen Analyse. H. U. Bergmeyer, editor. Verlag-Chemie, Weinheim. 253.

13. Wieland, O. 1962. Glycerin. In Methoden der enzymatischen Analyse. H. U. Bergmeyer, editor. VerlagChemie, Weinheim. 211.

14. Spackman, D. A., W. H. Stein, and S. Moore. 1958. Automatic recording apparatus for use in the chromatography of amino acids. Anal. Chem. 30: 1190.

15. Hagenfeldt, L. 1966. A gas chromatographic method for the determination of individual free fatty acids in plasma. Clin. Chim. Acta. 1.3: 266.

16. Hagenfeldt, L. 1968. The concentrations of individual free fatty acids in human plasma and their interrelationships. Ark. Kem. 29 : 57.

17. Aguilar-Parada, E., A. M. Eisentraut, and R. H. Unger. 1969. Pancreatic glucagon secretion in normal and diabetic subjects. Am. J. Med. Sci. 257: 415.

18. Rosselin, G., R. Assan, R. S. Yalow, and S. A. Berson. 1966. Separation of antibody-bound and unbound peptide hormones labelled with iodine- 131 by talcum powder and precipitated silica. Nature (Lond.). 212: 355.

19. Drabkin, D. L. 1950. Measurement of $\mathrm{O}_{2}$ saturation of blood by direct spectrophotometric determination. In Methods in Medical Research. J. H. Comroe, Jr., editor. Year Book Publishers, Chicago. 2: 159.

20. Drabkin, D. L., and J. H. Austin. 1935. Spectrophotometric studies. II. Preparations from washed blood cells; nitric oxide hemoglobin and sulfhemoglobin. $J$. Biol. Chem. 112 : 51.

21. Garby, L., and J. C. Vuille. 1961. The amount of trapped plasma in a high speed microcapillary hematocrit centrifuge. Scand. J. Clin. Lab. Invest. 13: 642.

22. Hagenfeldt, L., J. Wahren, B. Pernow, R. Cronestrand, and S. Ekeström. 1972. Free fatty acid metabolism of leg muscles during exercise in patients with obliterative iliac and femoral artery disease before and after reconstructive surgery. J. Clin. Invest. 51: 3061.

23. Hunter, W. M., and M. Y. Sukkar. 1968. Changes in plasma insulin levels during muscular exercise. $J$. Physiol. (Lond.). 196: 110 P.

24. Sanders, C. A., G. E. Levinson, W. H. Abelmann, and N. Freinkel. 1964. Effect of exercise on the peripheral utilization of glucose in man. N. Engl. J. Med. 271: 220.

25. Garland, P. B., E. A. Newsholme, and P. J. Randle. 1962. Effect of fatty acids, ketone bodies, diabetes and starvation on pyruvate metabolism in rat heart and diaphragm muscle. Nature (Lond.). 195: 381.

26. Randle, P. J., P. B. Garland, C. N. Hales, and E. A. Newsholme. 1963. The glucose fatty-acid cycle. Its role in insulin sensitivity and metabolic disturbances of diabetes mellitus. Lancet. 1: 785.

27. Hagenfeldt, L., and J. Wahren. 1971. Metabolism of free fatty acids and ketone bodies in skeletal muscle. In Muscle Metabolism During Exercise. B. Pernow and B. Saltin, editors. Plenum Press, New York. 153.

28. Ruderman, N. B., C. J. Toews, and E. Shafrir. 1969. Role of free fatty acids in glucose homeostasis. Arch. Intern. Med. 123: 299.

29. Marliss, E. B., T. T. Aoki, R. H. Unger, J. S. Soeldner, and G. F. Cahill, Jr. 1970. Glucagon levels and metabolic effects in fasting man. J. Clin. Invest. 49: 2256.

30. Felig, P., J. Wahren, R. Hendler, and G. Ahlborg. 1972. Plasma glucagon levels in exercising man. $N$. Engl. J. Med. 287 : 184.

31. Garcia, A., J. R. Williamson, and G. F. Cahill, Jr. 1966. Studies on the perfused rat liver. II. Effect of glucagon on gluconeogenesis. Diabetes. 15: 188.

32. Mallette, L. E., J. H. Exton, and C. R. Park. 1969. Effects of glucagon on amino acid transport and utilization in the perfused rat liver. J. Biol. Chem. 244: 5724.

33. Kibler, R. F., W. J. Taylor, and J. D. Myers. 1964. The effect of glucagon on net splanchnic balances of glucose, amino acid nitrogen, urea, ketones, and oxygen in man. J. Clin. Invest. 43: 904.

34. Unger, R. J. 1971. Insulin/glucagon ratio. In Impact 
of Insulin on Metabolic Pathways. E. Shafrir, editor. Academic Press, New York/London. 78.

35. Lefebvre, P. 1966. The physiological effect of glucagon on fat mobilization. Diabetologia. 2: 130.

36. Pozza, G. 1970. Cyclic AMP and the regulation of lipolysis in human adipose tissue incubated in vitro. In On the pathogenesis of diabetes mellitus. R. Luft and P. J. Randle, editors. Acta Diabetol. Lat. 7(Suppl. 1) : 300.

37. Edwards, H. T., R. Margaria, and D. B. Dill. 1934. Metabolic rate, blood sugar and the utilization of carbohydrate. Am. J. Physiol. 108: 203.

38. Bфje, O. 1935. Der Blutzucker während und nach körperlicher Arbeit. Munksgaard, Köpenhamn.

39. Young, D. R., R. Pelligra, and R. R. Adachi. 1966. Serum glucose and free fatty acids in man during prolonged exercise. J. Appl. Physiol. 21: 1047.

40. Ahlborg, B. 1967. Blood glucose during prolonged physical exercise in man. Försvarsmedicin. 3: 3 .
41. Felig, P., and J. Wahren. 1971. Amino acid metabolism in exercising man. J. Clin. Invest. 50: 2703.

42. Felig, P., J. Wahren, and L. Räf. 1973. Evidence of inter-organ amino acid transport by blood cells in humans. Proc. Nat. Acad. Sci. U. S. A. 70: 1775.

43. Wahren, J., P. Felig, E. Cerasi, and R. Luft. 1972. Splanchnic and peripheral glucose and amino acid metabolism in diabetes mellitus. J. Clin. Invest. 51: 1870.

44. Felig, P., O. E. Owen, J. Wahren, and G. F. Cahill, Jr. 1969. Amino acid metabolism during prolonged starvation. J. Clin. Invest. 48: 584.

45. Owen, O. E., A. P. Morgan, H. G. Kemp, J. M. Sullivan, M. G. Herrera, and G. F. Cahill, Jr. 1967. Brain metabolism during fasting. J. Clin. Invest. 46: 1589.

46. Hagenfeldt, L., and J. Wahren. 1971. Human forearm muscle metabolism during exercise. VI. Substrate utilization in prolonged fasting. Scand. J. Clin. Lab. Invest. $27: 299$. 